ARTICLE

\title{
Xenon iron oxides predicted as potential Xe hosts in Earth's lower mantle
}

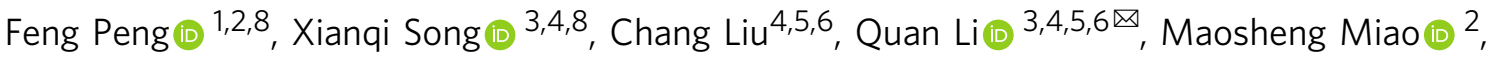 \\ Changfeng Chen (iD ${ }^{7 凶} \&$ Yanming Ma(D) ${ }^{3,4,5 凶}$
}

An enduring geological mystery concerns the missing xenon problem, referring to the abnormally low concentration of xenon compared to other noble gases in Earth's atmosphere. Identifying mantle minerals that can capture and stabilize xenon has been a great challenge in materials physics and xenon chemistry. Here, using an advanced crystal structure search algorithm in conjunction with first-principles calculations we find reactions of xenon with recently discovered iron peroxide $\mathrm{FeO}_{2}$, forming robust xenon-iron oxides $\mathrm{Xe}_{2} \mathrm{FeO}_{2}$ and $\mathrm{XeFe}_{3} \mathrm{O}_{6}$ with significant $\mathrm{Xe}-\mathrm{O}$ bonding in a wide range of pressure-temperature conditions corresponding to vast regions in Earth's lower mantle. Calculated mass density and sound velocities validate $\mathrm{Xe}-\mathrm{Fe}$ oxides as viable lower-mantle constituents. Meanwhile, Fe oxides do not react with $\mathrm{Kr}, \mathrm{Ar}$ and $\mathrm{Ne}$. It means that if $\mathrm{Xe}$ exists in the lower mantle at the same pressures as $\mathrm{FeO}_{2}$, xenon-iron oxides are predicted as potential Xe hosts in Earth's lower mantle and could provide the repository for the atmosphere's missing Xe. These findings establish robust materials basis, formation mechanism, and geological viability of these $\mathrm{Xe}-\mathrm{Fe}$ oxides, which advance fundamental knowledge for understanding xenon chemistry and physics mechanisms for the possible deep-Earth Xe reservoir.

\footnotetext{
${ }^{1}$ College of Physics and Electronic Information \& Henan Key Laboratory of Electromagnetic Transformation and Detection, Luoyang Normal University, 471022 Luoyang, China. ${ }^{2}$ Department of Chemistry and Biochemistry, California State University Northridge, Northridge, CA 91330-8262, USA. ${ }^{3}$ State Key Laboratory of Superhard Materials, College of Physics, Jilin University, 130012 Changchun, China. ${ }^{4}$ Innovation Center for Computational Methods \& Software, College of Physics, Jilin University, 130012 Changchun, China. ${ }^{5}$ International Center of Future Science, Jilin University, 130012 Changchun, China. ${ }^{6}$ Key Laboratory of Automobile Materials of MOE and Department of Materials Science, College of Materials Science and Engineering, Jilin University, 130012 Changchun, China. ${ }^{7}$ Department of Physics and Astronomy, University of Nevada, Las Vegas, NV 89154, USA. ${ }^{8}$ These authors contributed equally:

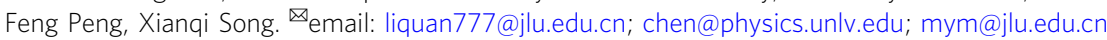


T he chemical reaction of inert xenon (Xe), a quintessential full-shell element, was earliest predicted by Pauling in 1933 and the first xenon compound was experimentally produced in $1962^{1}$. Then, more xenon compounds were experimentally synthesized at ambient pressure, containing some most electronegative atoms like fluorine ${ }^{2-5}$ or oxygen ${ }^{6-9}$. Subsequently, scientists found that pressure can effectively improve the chemical reactivity of $\mathrm{Xe}^{10-17}$. At moderate pressures, solid xenon forms weakly bonded compounds with other species, e.g., with $\mathrm{H}_{2} \mathrm{O}^{10}$ and $\mathrm{O}_{2}{ }^{11,12}$ at 1 and $3 \mathrm{GPa}$, respectively. Strikingly, several novel $\mathrm{Xe}$ compounds with unusual stoichiometries are found to be thermodynamically stable at high pressures, e.g., Xe oxides ${ }^{13,14}$, Xe nitrides $^{15}$, xenon-hydrogen ${ }^{16}$, and Xe-Mg compounds ${ }^{17}$.

At ultra-high-pressure conditions, the high volatility, relative chemical inertia, and abundant isotopes of xenon make it a valuable tracer in the study of evolutionary dynamics and history of Earth. However, 99\% of Earth's primordial Xe is mysteriously missing as characterized by its very low abundance compared to other noble gases in Earth's atmosphere ${ }^{18}$, which is known as the missing Xe problem ${ }^{19}$. Early hypotheses proposed that Xe might have escaped from the atmosphere after ionization ${ }^{20-22}$, or that it might be stored in the interior of Earth $^{23-29}$. Attempts to incorporate Xe into ices, clathrates and sediments in the Earth's crust were not successful ${ }^{27-29}$. Laboratory experiments have succeeded in trapping Xe in quartz ${ }^{30,31}$ and observing predicted stable xenon oxides ${ }^{13,14,32}$; but these results cannot explain the missing Xe mystery, because xenon oxides are unstable in equilibrium with metallic iron in lower mantle while xenon silicates decompose spontaneously at mantle pressures ${ }^{13}$. Reactions of Xe with iron and nickel in Earth's core were predicted as a viable scenario $^{33}$ and the predicted compounds were synthesized under core pressure and temperature conditions ${ }^{32,34}$. However, it remains highly intriguing and challenging to explore possible capture and stabilization of Xe by suitable minerals in Earth's mantle, which is of special significance because it was estimated that the loss of atmospheric Xe occurred about 100 million years from accretion, corresponding to the time of mantle differentiation event ${ }^{30}$.

Extensive past searches were unable to find chemical reactions of Xe with known mantle minerals. Recently discovered $\mathrm{FeO}_{2}$ synthesized at lower mantle conditions ${ }^{35}$ and stablized above 74 $\mathrm{GPa}$ in theoretical calculation ${ }^{36}$, offer an intriguing new possibility. This newly identified iron peroxide is able to react with helium to form a rare helium-bearing compound that explains deep-Earth primordial helium deposits revealed by geochemical evidences ${ }^{37}$. This finding raises exciting prospects that $\mathrm{FeO}_{2}$ may be able to react with Xe (actually $P-T$ stability range of $\mathrm{FeO}_{2}$ has not been completely established in experiments) at mantle conditions, thereby forming compounds capable of trapping Xe in Earth's interior. In this work, we have explored possible reactions of Xe with $\mathrm{FeO}_{2}$ in contrast with known mantle constituents $\mathrm{FeO}$, $\mathrm{SiO}_{2}, \mathrm{MgO}, \mathrm{CaO}$, and $\mathrm{Al}_{2} \mathrm{O}_{3}$. We find that $\mathrm{FeO}_{2}$ has unique ability to react with $\mathrm{Xe}$ and form robust Xe-Fe oxides $\mathrm{Xe}_{2} \mathrm{FeO}_{2}$ and $\mathrm{XeFe}_{3} \mathrm{O}_{6}$ with surprisingly strong $\mathrm{Xe}-\mathrm{O}$ bonding, while other mantle oxides do not react with Xe. We have further examined mass density and sound velocities of these Xe-Fe oxides, and the results support their viability in vast lower mantle region. These findings establish robust materials basis, formation mechanism, and geological viability of these Xe-Fe oxides, which advance fundamental knowledge for understanding xenon chemistry and physics mechanisms for the possible deep-Earth Xe reservoir.

\section{Results}

Crystal structures. We take the crystal phases identified by the structure search process at various $\mathrm{FeO}_{2}$ : Xe ratios and compute their enthalpy to determine the most viable structure at each composition, and based on the obtained results we construct the convex hull, as shown in Fig. 1a, which indicates stable products from reactions of $\mathrm{FeO}_{2}$ and Xe. This exercise has led to the discovery of two Xe-Fe oxides, $\mathrm{Xe}_{2} \mathrm{FeO}_{2}$ and $\mathrm{XeFe}_{3} \mathrm{O}_{6}$, that are stable against decomposition at $150 \mathrm{GPa}$ and $200 \mathrm{GPa}$. The pressurevolume terms, associated with packing efficiency, make the major contribution to guarantee the thermodynamical stability of $\mathrm{Xe}_{2} \mathrm{FeO}_{2}$ and $\mathrm{XeFe}_{3} \mathrm{O}_{6}$ with formation enthalpies lying on the convex hull (Supplementary Fig. 1). These two Xe-Fe oxides are both still stable relative to all possible binary phases or pure simple substances of Xe-Fe- $\mathrm{O}_{2}$, which can be seen in Supplementary Information (Supplementary Figs. 2 and 3). The details Phonon dispersions calculated at $150 \mathrm{GPa}$ (Fig. 1b, c) show that these compounds are dynamically stable and, as will be shown below, thermal effects further stabilize both oxides over a wider range of pressure at elevated temperatures at deep-Earth conditions. Here we first present a full analysis of structural and bonding characters of these two oxides at $150 \mathrm{GPa}$ as a representative case study. The compound $\mathrm{Xe}_{2} \mathrm{FeO}_{2}$ is crystalized in a monoclinic structure with $P 2_{1} / c$ symmetry (Fig. 1d); its structural motif consists of stacked layers of corner-sharing octahedron with each $\mathrm{Fe}$ atom surrounded by six $\mathrm{O}$ atoms and the $\mathrm{Fe}$ atom is centered in a slightly distorted octahedron containing $\mathrm{Fe}-\mathrm{O}$ bond lengths in a narrow range of $1.79-1.82 \AA$ at $150 \mathrm{GPa}$. Each Xe atom in this structure has a coordination number of 3 , bonding at the corners of $\mathrm{FeO}_{6}$ octahedra with the $\mathrm{Xe}-\mathrm{O}$ bond lengths in the range of 2.40-2.42 $\AA$ at $150 \mathrm{GPa}$, which are similar to those found in $\mathrm{Xe}_{2} \mathrm{O}_{3}(\sim 2.50 \AA)$ and $\mathrm{Xe}_{2} \mathrm{O}_{5}(\sim 2.37 \AA)$ at the same pressure ${ }^{38}$. Meanwhile, $\mathrm{XeFe}_{3} \mathrm{O}_{6}$ is stabilized in a triclinic structure with $P$ 1 symmetry, containing two formula units per cell (Fig. 1e); its corner-sharing $\mathrm{FeO}_{6}$ octahedra host $\mathrm{Fe}-\mathrm{O}$ bonds with lengths of $1.73-1.81 \AA$ at $150 \mathrm{GPa}$, forming a tubular structure, and each Xe atom has a coordination number of 6 , located in the $\mathrm{Fe}-\mathrm{O}$ tube with the nearest Xe-O distance of $2.08 \AA$, resulting in the vibrational mode of the lowest-frequency branch at $\mathrm{F}$ as shown in Fig. 1c. Further vibrational analyses are shown in Supplementary Fig. 4 and structural details of both Xe-Fe oxides at $150 \mathrm{GPa}$ are listed in Supplementary Information (Supplementary Table 1).

\section{Discussion}

Chemical Bonding. To assess bonding characters in the two XeFe oxides, we have calculated their electronic density of states (DOS) at $150 \mathrm{GPa}$. The results shown in Fig. 2a, c reveal metallic nature of these compounds; crucially, in both cases the DOS in the vicinity of the Fermi level contain significant contributions from the Fe $3 \mathrm{~d}$, Xe 5p and O 2p states, indicating considerable $\mathrm{Fe}-\mathrm{O}$ and $\mathrm{Xe}-\mathrm{O}$ bonding interactions. We further calculated projected crystal orbital Hamiltonian population (pCOHP) that evaluates weighted population of wavefunctions on two atomic orbitals of a pair of selected atoms ${ }^{39}$. The results in Fig. $2 \mathrm{~b}, \mathrm{~d}$ reveal characteristic $\mathrm{Fe}-\mathrm{O}$ and $\mathrm{Xe}-\mathrm{O}$ covalent bonding as indicated by the prominent features of strong low-energy bonding states together with some occupied antibonding states near the Fermi level in each case. It is noted that the occupied bonding states in $\mathrm{Xe}_{2} \mathrm{FeO}_{2}$ occur deeper below the Fermi level compared to those in $\mathrm{XeFe}_{3} \mathrm{O}_{6}$, indicating higher stability of $\mathrm{Xe}_{2} \mathrm{FeO}_{2}$. Moreover, integrated COHP (ICOHP) provides an estimate of the overall bonding strength ${ }^{39}$. Calculated ICOHP values for the $\mathrm{Fe}-\mathrm{O}$ and $\mathrm{Xe}-\mathrm{O}$ bonds at $150 \mathrm{GPa}$ are $-1.45 \mathrm{eV} /$ pair and -0.24 $\mathrm{eV} /$ pair in $\mathrm{XeFe}_{3} \mathrm{O}_{6}$ and $-1.01 \mathrm{eV} /$ pair and $-0.12 \mathrm{eV} /$ pair in $\mathrm{Xe}_{2} \mathrm{FeO}_{2}$, respectively. These results show considerable $\mathrm{Xe}-\mathrm{O}$ bonding compared to the strong $\mathrm{Fe}-\mathrm{O}$ bonding, in sharp contrast to recently discovered $\mathrm{He}-\mathrm{FeO}_{2}$ compound where $\mathrm{He}$ atoms show little direct bonding ${ }^{37}$ but instead serve as a Coulomb shield in 

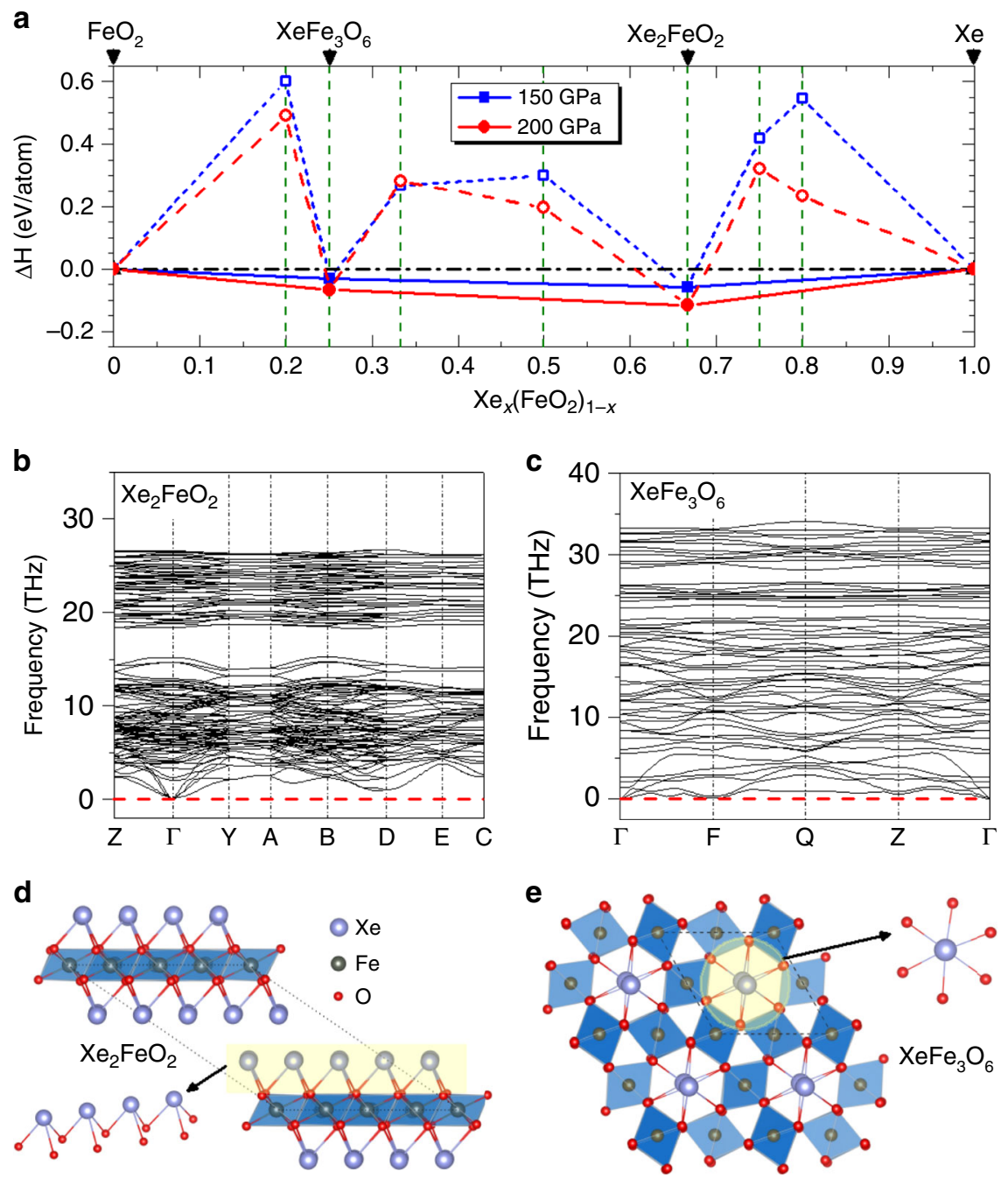

Fig. 1 Energetic stability and structures of Xe-Fe oxides. a The ground-state convex hull with solid lines for the $\mathrm{FeO}_{2}-\mathrm{Xe}$ system constructed from calculated formation enthalpy $(\Delta H)$ data, identifying two stable $\mathrm{Xe}$-Fe oxides, $\mathrm{Xe}_{2} \mathrm{FeO}_{2}$ and $\mathrm{XeFe}_{3} \mathrm{O}_{6}$, at $150 \mathrm{GPa}$ and $200 \mathrm{GPa}$. The solid and open symbols represent the stable structures lying on the convex hull and the unstable structures above the convex hull, respectively. $\mathbf{b}$ Phonon dispersions of $\mathrm{Xe}_{2} \mathrm{FeO}_{2}$ at $150 \mathrm{GPa}$. c Phonon dispersions of $\mathrm{Xe}_{3} \mathrm{FeO}_{6}$ at $150 \mathrm{GPa}$. d The structure of $\mathrm{Xe}_{2} \mathrm{FeO}_{2}$ with a polyhedral and an enlarged view. e The structure of $\mathrm{Xe}_{3} \mathrm{FeO}{ }_{6}$ with a polyhedral and an enlarged view. $\mathrm{Xe}, \mathrm{Fe}$, and $\mathrm{O}$ atoms are, respectively, shown in purple, gray, and red spheres.

stabilizing the structure ${ }^{40}$. We also examined charge distribution in $\mathrm{Xe}_{2} \mathrm{FeO}_{2}$ and $\mathrm{XeFe}_{3} \mathrm{O}_{6}$ by a Bader charge analysis ${ }^{41}$, and the results reveal a considerable amount of highly unusual charge transfer from $\mathrm{Fe}$ and $\mathrm{Xe}$ to $\mathrm{O}$ atoms. At $150 \mathrm{GPa}$, the Bader partial charges in $\mathrm{Xe}_{2} \mathrm{FeO}_{2}$ are $+0.30,+1.40,-1.00$ for $\mathrm{Xe}, \mathrm{Fe}$, and $\mathrm{O}$, respectively; meanwhile, Bader partial charges in $\mathrm{XeFe}_{3} \mathrm{O}_{6}$ are $+1.35,+1.35,-0.90$ for $\mathrm{Xe}, \mathrm{Fe}$, and $\mathrm{O}$, respectively, at the same pressure. As a result, $\mathrm{Xe}$ atoms in $\mathrm{XeFe}_{3} \mathrm{O}_{6}$ can donate more electrons than in $\mathrm{Xe}_{2} \mathrm{FeO}_{2}$ and $\mathrm{Xe}$ atoms can display different valence states in $\mathrm{FeO}_{2}-\mathrm{Xe}$ compounds. These significant charge transfers once again indicate strong bonding formation involving $\mathrm{Xe}$, which is rare among noble gases atoms.

Thermal effect. Thermal effects play a crucial role in material stability at pertinent geophysical conditions, where temperatures reach $2000-4500 \mathrm{~K}$. Here, we evaluate Gibbs free energy of $\mathrm{Xe}_{2} \mathrm{FeO}_{2}$ and $\mathrm{XeFe}_{3} \mathrm{O}_{6}$ by calculating lattice contributions to the entropic term using the quasiharmonic approximation to account for volume dependence of phonon frequencies due to temperature induced lattice expansion. In Fig. $3 \mathrm{a}$ we present relevant energetic terms affecting structure stability. It is seen that internal energy $U$ values of the two Xe-Fe oxides are higher than those of their separate constituents, namely $\mathrm{Xe}$ and $\mathrm{FeO}_{2}$, but the $P V$ terms are decisively favorable and dominant, producing the lower enthalpy $H$ for the formation of both oxides. The temperature effect (i.e., thermal vibration of atomic positions) are favorable to reduce Gibbs free energy $G$ of the Xe-Fe oxides even more relative to their separate constituents, further stabilizing the resulting crystal structures. Consequently, the threshold pressure above which these oxides are stable reduces considerably at increasing temperatures, thereby significantly expanding their stability field as will be seen in the phase diagram presented below.

Phase diagram. For a full assessment of temperature effects, we have performed extensive energetic and ab initio molecular dynamics (AIMD) simulations to evaluate structural stability and construct pressure-temperature $(P-T)$ phase diagram for the XeFe oxide system. We present in Fig. $3 b, c$ the mean square deviations (MSD) of atomic positions in the Xe-Fe oxides at typical high $P-T$ conditions of $150 \mathrm{GPa}$ and $3000 \mathrm{~K}$, and the results show that the $\mathrm{Fe}, \mathrm{O}$, and $\mathrm{Xe}$ atoms all remain near their lattice sites, indicating stability of the crystal structure. Similar AIMD simulations were performed systematically to probe each phase and determine the boundary where temperature-driven 

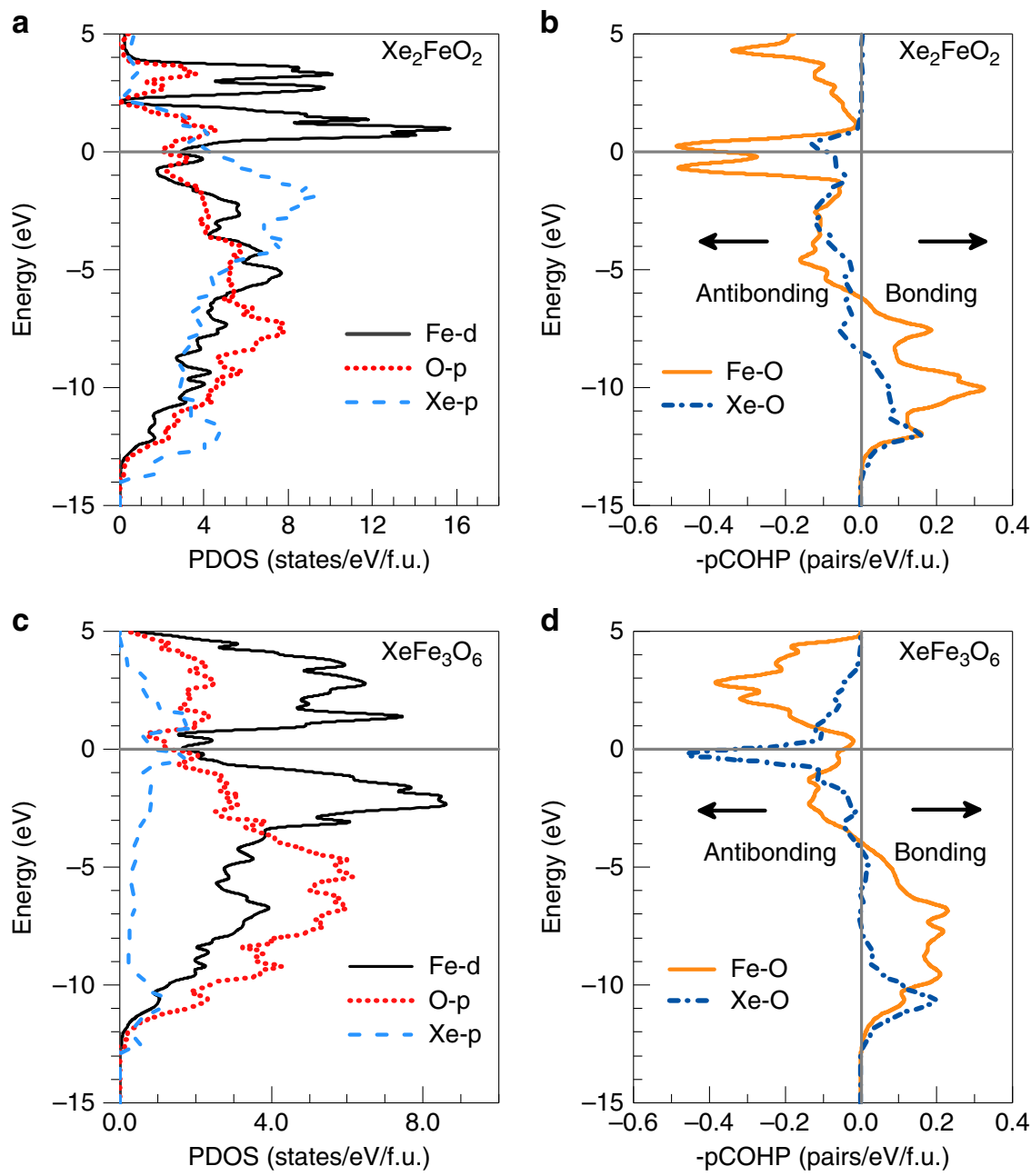

Fig. 2 Electronic properties of the two Xe-Fe oxides at $\mathbf{1 5 0} \mathbf{~ G P a}$. a Projected density of states (PDOS) of Fe-d, O-p, and $\mathrm{Xe}^{-p}$ orbitals in $\mathrm{Xe}{ }_{2} \mathrm{FeO}{ }_{2}$. b Projected crystal orbital Hamiltonian Population (-pCOHP) of the newly predicted $\mathrm{Xe}_{2} \mathrm{FeO}_{2}$ compound. The values of -pCOHP $>0$ signify bonding states and the values of $-\mathrm{pCOHP}<0$ signify antibonding states. $\mathbf{c}$ PDOS of Fe-d, O-p, and Xe-p orbitals in $\mathrm{XeFe}_{3} \mathrm{O}_{6}$. $\mathbf{d}-\mathrm{pCOHP}$ of the newly predicted $\mathrm{XeFe}_{3} \mathrm{O}_{6}$ compound. The Fermi energy is set to zero of the energy.

instability sets as indicated by deviating MSD from equilibrium positions; meanwhile Gibbs free energies were computed and compared to determine the boundaries between different solid phases in the $P-T$ space. The resulting phase diagram (Fig. 4) spans a wide $P-T$ range covering the lower mantle and higher $P_{-}$ $T$ regions.

We now analyze the stability fields of the predicted Xe-Fe oxides under the $(P, T)$ conditions conforming to geological constraints dictated by the geotherm that is also shown in Fig. 4. It is seen that $\mathrm{Xe}_{2} \mathrm{FeO}_{2}$ is stable in the pressure range 110-120 $\mathrm{GPa}$ and temperatures around $2500 \mathrm{~K}$ inside the geotherm corresponding to the deep lower mantle region; meanwhile, both $\mathrm{Xe}_{2} \mathrm{FeO}_{2}$ and $\mathrm{XeFe}_{3} \mathrm{O}_{6}$ are stable between pressures $120-136 \mathrm{GPa}$ and temperatures $2500-3600 \mathrm{~K}$ inside the geotherm corresponding to the lowest mantle to core-mantle boundary (CMB); finally, as pressure and temperature rise further, $\mathrm{Xe}_{2} \mathrm{FeO}_{2}$ becomes the sole stable phase.

The above results suggest stable Xe-Fe oxides under the $(P, T)$ conditions in vast deep-Earth regions. It is, however, necessary to assess the viability of the predicted Xe-Fe oxides in geological environments by examining their key material characteristics. To this end, we have run AIMD simulations to determine crystal structures at selected $(P, T)$ conditions and used an AIMD-based strain-stress method ${ }^{42,43}$ to calculate the elastic tensors, from which elastic-wave velocities were determined by solving the Christoffel equation det $\left|T_{i k}-\delta_{i k} \rho V^{2}\right|=0$, where $\delta_{i k}$ is the Kronecker delta function, $V$ is one of the seismic velocities, and $T_{i k}$ is the Christoffel stiffness ${ }^{4}$.

Mass density and sound velocities. We examine mass density and mean compressional ( $P$-wave) and shear ( $S$-wave) sound velocities, $V_{P}$ and $V_{S}$, respectively, at two representative $(P, T)$ points: $(120 \mathrm{GPa}, 2500 \mathrm{~K})$ for lower mantle, and $(135 \mathrm{GPa}, 3500$ $\mathrm{K})$ for $\mathrm{CMB}$, and compare with geological data. We first examine $\mathrm{XeFe}_{3} \mathrm{O}_{6}$, whose stability field compared to the geotherm indicates its stability in the lower mantle and CMB regions, but higher temperatures destabilize this compound. The calculated densities of $\mathrm{XeFe}_{3} \mathrm{O}_{6}$ are 8.86 and $9.06 \mathrm{~g} / \mathrm{cm}^{3}$ at the selected lower mantle and $\mathrm{CMB}(P, T)$ points, respectively, which lie within or close to the range of $4.95-9.90 \mathrm{~g} / \mathrm{cm}^{3}$ from the core rigidity zone (CRZ) model and the range of $5.57-8.91 \mathrm{~g} / \mathrm{cm}^{3}$ from the ultralow velocity zone (ULVZ) model ${ }^{45}$. The calculated $V_{P}\left(V_{S}\right)$ are 8.94(4.03) $\mathrm{km} / \mathrm{s}$ and $9.20(4.26) \mathrm{km} / \mathrm{s}$, respectively, which lie within the range of $8.20-10.70 \mathrm{~km} / \mathrm{s}(1.00-5.00 \mathrm{~km} / \mathrm{s})$ for the ULVZs ${ }^{45}$. All these results indicate that $\mathrm{XeFe}_{3} \mathrm{O}_{6}$ is a viable constituent at the lower mantle and $\mathrm{CMB}(P, T)$ conditions.

The calculated densities of $\mathrm{Xe}_{2} \mathrm{FeO}_{2}$ are 9.78 and $9.87 \mathrm{~g} / \mathrm{cm}^{3}$ at the lower mantle and $\mathrm{CMB}$ points, respectively, which lie outside 

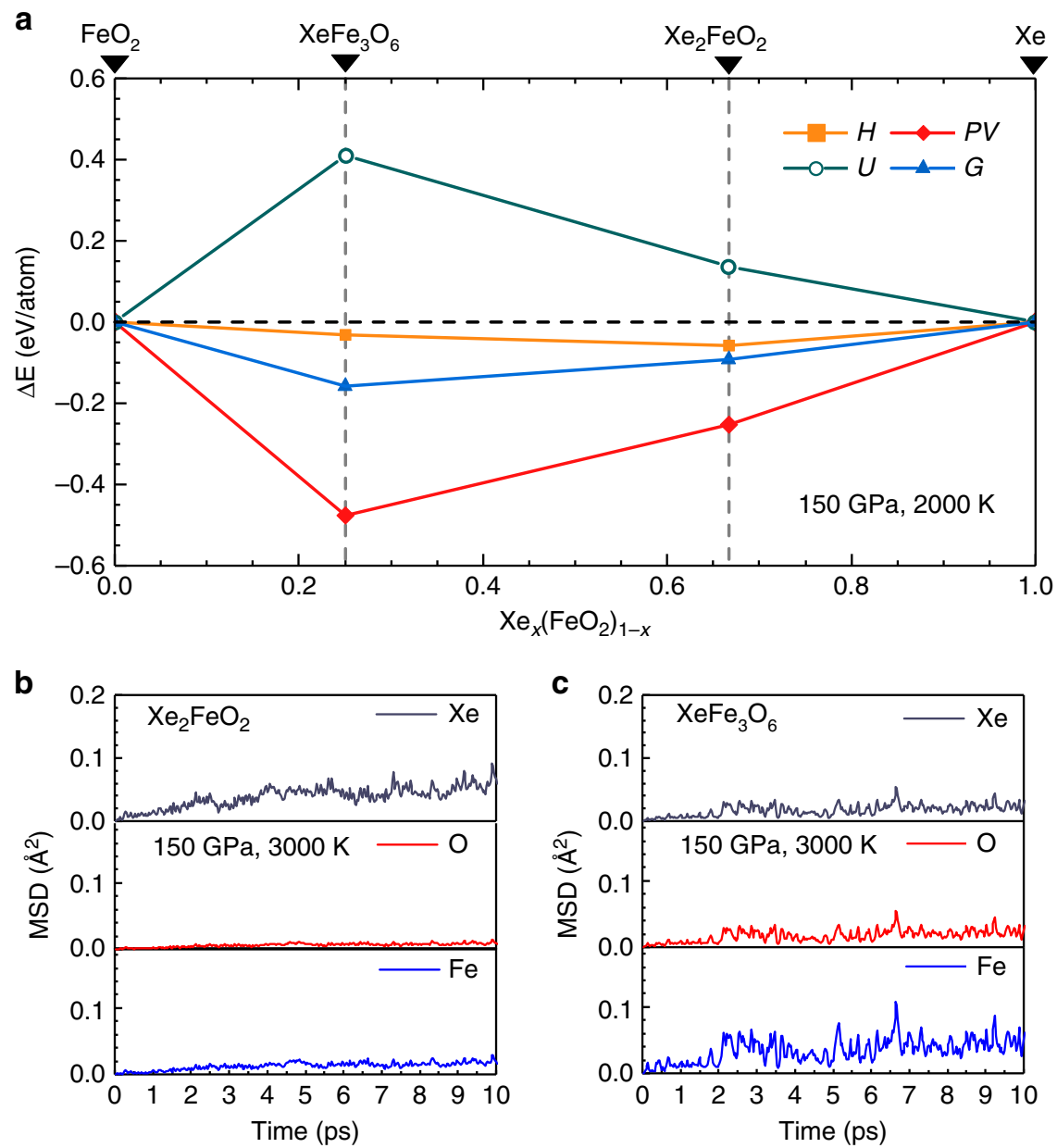

Fig. 3 Calculated energetic terms and the mean square deviations. a Various energetic term $(\Delta E)$ for the two Xe-Fe oxides, enthalpy $(H)$, pressure-volume (PV) terms, internal energy (U), and Gibbs free energy (G) at $150 \mathrm{GPa}, 2000 \mathrm{~K}$. b Mean square deviations (MSD) of Xe, O, and Fe atomic positions in $\mathrm{Xe}_{2} \mathrm{FeO}_{2}$ at $150 \mathrm{GPa}, 3000 \mathrm{~K}$. c MSD of $\mathrm{Xe}, \mathrm{O}$, and $\mathrm{Fe}$ atomic positions in $\mathrm{XeFe}_{3} \mathrm{O}_{6}$ at $150 \mathrm{GPa}, 3000 \mathrm{~K}$.

the range of $5.57-8.91 \mathrm{~g} / \mathrm{cm}^{3}$ from the ULVZ model and at the top of the range of $4.95-9.90 \mathrm{~g} / \mathrm{cm}^{3}$ from the CRZ model ${ }^{45}$. The calculated $V_{P}\left(V_{S}\right)$ are $7.83(4.21) \mathrm{km} / \mathrm{s}$ and $7.94(4.02) \mathrm{km} / \mathrm{s}$ at the lower mantle and CMB points, respectively. While these $V_{S}$ values lie within the range of $1.00-5.00 \mathrm{~km} / \mathrm{s}$ from the CRZ model or the range $2.91-6.17 \mathrm{~km} / \mathrm{s}$ from the ULVZ model ${ }^{45}$, the $V_{P}$ values are out of the range of $10.97-13.03 \mathrm{~km} / \mathrm{s}$ from the ULVZ model or the range of $8.20-10.70 \mathrm{~km} / \mathrm{s}$ from the CRZ model ${ }^{45}$. These results render $\mathrm{Xe}_{2} \mathrm{FeO}_{2}$ a marginal lower mantle or $\mathrm{CMB}$ constituent at best.

Reaction of noble gases and deep-Earth constituents. Finally, we highlight several significant aspects on the special role of $\mathrm{FeO}_{2}$ in trapping $\mathrm{Xe}$ in deep Earth. First, we have systematically examined possible reaction of $\mathrm{Xe}$ with major deep-Earth constituents $\mathrm{FeO}, \mathrm{SiO}_{2}, \mathrm{MgO}, \mathrm{CaO}$, and $\mathrm{Al}_{2} \mathrm{O}_{3}$, and the resulting convex-hull data (Supplementary Fig. 5) show highly unfavorable energetics in all the cases, offering an underlying cause for unsuccessful past attempts to find Xe-bearing minerals in Earth's mantle. Second, we have examined possible reactions of other noble gases $\mathrm{Ne}, \mathrm{Ar}$, and $\mathrm{Kr}$ with $\mathrm{FeO}_{2}$, and the results (Supplementary Fig. 6) indicate no tendency toward forming any stable noble-gas-Fe oxides up to $200 \mathrm{GPa}$. These results provide the possibility that Xe could be the sole inert element for reacting with deep-Earth constituents under mantle conditions. Moreover, while He-bearing compound $\mathrm{FeO}_{2} \mathrm{He}$ is found stable at $\mathrm{CMB}$ conditions, there is little direct bonding between $\mathrm{He}$ and $\mathrm{Fe}$ or $\mathrm{O}$ atoms in the compound ${ }^{37}$. Compared to $\mathrm{Kr}, \mathrm{Ar}, \mathrm{Ne}$, and $\mathrm{He}, \mathrm{Xe}$ has the lowest ionization energy and electronegativity, and consequently $\mathrm{Xe}$ is the easiest noble-gas atom to open up its outermost closed shell and form direct bonding as found in $\mathrm{Xe}_{2} \mathrm{FeO}_{2}$ and $\mathrm{XeFe}_{3} \mathrm{O}_{6}$.

In summary, we have identified two Xe-Fe oxides, $\mathrm{Xe}_{2} \mathrm{FeO}_{2}$ and $\mathrm{XeFe}_{3} \mathrm{O}_{6}$, that are the first viable Xe-bearing compound at Earth's lower mantle conditions. These new compounds are predicted by extensive crystal structure search in conjunction with ab initio energetic calculations and molecular dynamics simulations. Mass densities and compressional and shear sound velocities calculated at deep-Earth conditions are compatible with pertinent ULVZ and PREM data, thus confirming viability of $\mathrm{Xe}_{2} \mathrm{FeO}_{2}$ in geological environments. These results provide compelling evidence for a distinct deep-Earth Xe reservoir beyond previously proposed $\mathrm{Xe}-\mathrm{Fe}$ and $\mathrm{Xe}-\mathrm{Ni}$ intermetallic compounds in Earth's inner core, thereby greatly expanding the range and scope of Xebearing compounds in deep Earth. The Xe-Fe oxides may enrich the understanding of prominent geophysical and geochemical processes, such as seismic anomalies near the CMB and possibly new chemical reactions inside Earth's lower mantle.

\section{Methods}

Structural predictions. Our structure search is based on a global optimization of free-energy surfaces using the CALYPSO methodology 46,47 , which has been successfully employed in predicting a large variety of crystal structures ${ }^{48-52}$. Evolutionary variable-cell calculations were performed at 120,150 , and $200 \mathrm{GPa}$ with 1 , 


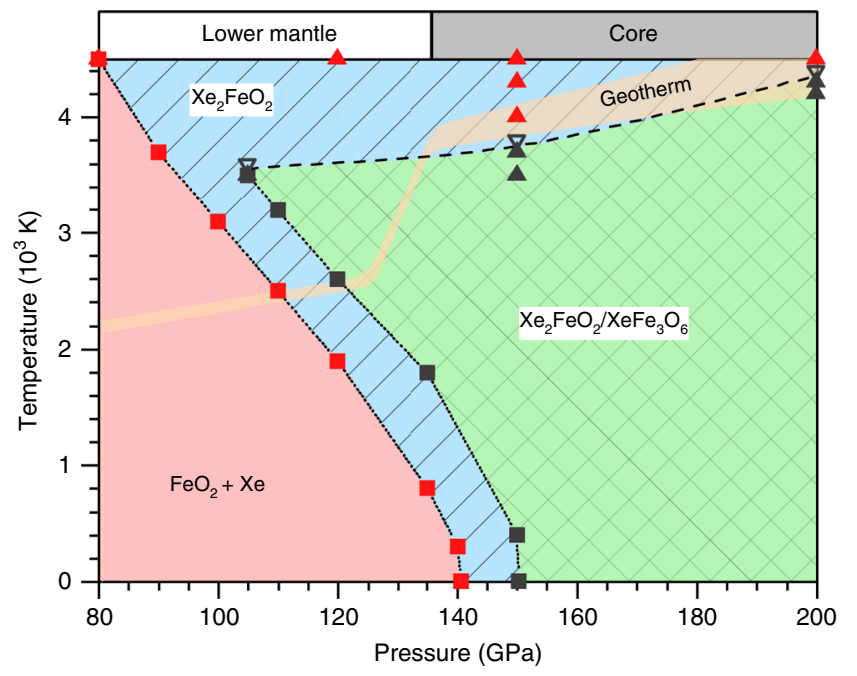

Fig. 4 The Pressure-temperature $(P-T)$ phase diagram of the $\mathrm{Xe}^{-} \mathrm{FeO}_{2}$ system. The dotted and dashed lines indicate phase boundaries and temperature-driven phase instability, which are determined by Gibbs free energy and ab initio molecular dynamics (AIMD) calculations, respectively. The square symbols show phase transition points based on relative Gibbs free energy, and the solid and open triangle symbols represent stable and temperature-driven unstable solid phases, respectively, determined by AIMD simulations. The $P-T$ regions of stable $\mathrm{Xe}_{2} \mathrm{FeO}_{2}$ are covered by slash lines and the $P-T$ regions of stable $\mathrm{XeFe}_{3} \mathrm{O}_{6}$ are filled by back-slash. The pressure boundary between the lower mantle and the core is shown at the top of the figure. Also shown is the geotherm of the Earth's interior 65 .

2, 3, and 4 formula units (f. u.) per cell. Most searches converge in 50 generations with about 2500 structures generated.

Ab initio calculations. First-principles total-energy and electronic property calculations were carried out using the density functional theory with the Perdew-Burke-Ernzerhof exchange-correlation functional in the generalized gradient approximation (GGA) $)^{53,54}$ as implemented in the VASP $\operatorname{code}^{55}$, adopting frozen-core all-electron projector-augmented wave method ${ }^{56}$ with $3 s^{2} 3 \mathrm{p}^{6} 3 \mathrm{~d}^{7} 4 \mathrm{~s}^{1}$, $2 s^{2} 2 p^{4}$, and $4 d^{10} 5 s^{2} 5 p^{6}$ treated as valence electrons for Fe, $\mathrm{O}$, and Xe, respectively. Correlation effects among the Fe $3 \mathrm{~d}$ electrons were treated in the GGA + U approach $^{57,58}$, adopting the recently proposed on-site Coulomb interaction $U=$ $5.0 \mathrm{eV}$ and a Hund's coupling $J=0.8 \mathrm{Ev}^{36,59-61}$. The spin-polarized and magnetic states were considered in obtaining the total-energy of the compounds containing iron. Zero-point energy was included in all reported calculations. A cutoff energy of $1200 \mathrm{eV}$ for the plane-wave expansion and fine Monkhorst-Pack $\mathbf{k}$ meshes ${ }^{62}$ were chosen to ensure enthalpy convergence of better than $1 \mathrm{meV} / \mathrm{atom}$.

Phonon calculations. To determine the dynamical stability, we performed phonon calculations by the direct supercell method using the Hellmann-Feynman theorem, as implemented in Phonopy code ${ }^{63}$. The harmonic interatomic force constants are calculated by $3 \times 3 \times 3$ and $3 \times 2 \times 2$ supercells for $P 2_{1} / \mathrm{c}-\mathrm{Xe}_{2} \mathrm{FeO}_{2}$ and $P-1$ $\mathrm{XeFe}_{3} \mathrm{O}_{6}$, respectively. Forces were calculated for atomic displacements of $0.01 \AA$, with a convergence threshold of $1 \times 10^{-5} \mathrm{eV} / \AA ̊$.

Van der Waals interaction. To examine the contribution of $\mathrm{vdW}$ interaction to the lattice energy, we have calculated the enthalpy of formation of $\mathrm{Xe}_{2} \mathrm{FeO}_{2}$ at high pressures using the vdW-DF2 density functional ${ }^{64}$. Our results show that the enthalpy of formation is less sensitive to the contribution of vdW correction at high-pressure conditions for $\mathrm{Xe}^{-} \mathrm{FeO}_{2}$ compounds, e.g., about $0.6 \mathrm{meV} /$ atom for $P 2_{1} / c \mathrm{Xe}_{2} \mathrm{FeO}_{2}$ at $135 \mathrm{GPa}$, thus vdW interaction is not considered in the calculations of lattice energy.

\section{Data availability}

The authors declare that the main data supporting the findings of this study are contained within the paper and its associated Supplementary Information. All other relevant data are available from the corresponding author upon reasonable request.

\section{Code availability}

CALYPSO code is free for academic use, by registering at http://www.calypso.cn. The other scripts are available from the authors upon reasonable request.
Received: 15 March 2020; Accepted: 25 September 2020; Published online: 16 October 2020

\section{References}

1. Bartlett, N. Xenon hexafluoroplatinate(v) $\mathrm{Xe}^{+}\left[\mathrm{PtF}_{6}\right]^{-}$. Proc. Chem. Soc. 1, 218 (1962).

2. Chernick, C. L. et al. Fluorine compounds of xenon and radon. Science 138, 136-138 (1962).

3. Claassen, H. H., Selig, H. \& Malm, J. G. Xenon tetrafluoride. J. Am. Chem. Soc. 84, 3593 (1962).

4. Gavin JR, R. M. \& Bartell, L. S. Molecular structure of $\mathrm{XeF}_{6}$. I. Analysis of electron-diffraction intensities. J. Chem. Phys. 48, 2460-2465 (1968).

5. Hoppe, R., Daehne, W., Mattauch, H. \& Roedder, K. Fluorination of xenon. Angew. Chem. Int. Ed. Engl. 1, 599 (1962).

6. Smith, D. F. Xenon trioxide. J. Am. Chem. Soc. 85, 816-817 (1963).

7. Templeton, D. H., Zalkin, A., Forrester, J. D. \& Williamson, S. M. Crystal and molecular structure of xenon trioxide. J. Am. Chem. Soc. 85, 817 (1963).

8. Huston, J. L., Studier, M. H. \& Sloth, E. N. Xenon tetroxide: mass spectrum. Science 143, 1161 (1964).

9. Selig, H., Claassen, H. H., Chernick, C. L., Malm, J. G. \& Huston, J. L. Xenon tetroxide: preparation and some properties. Science 143, 1322-1323 (1964).

10. Sanloup, C., Mao, H.-K. \& Hemley, R. J. High-pressure transformations in xenon hydrates. Proc. Natl Acad. Sci. USA 99, 25-28 (2002).

11. Dewaele, A., Loubeyre, P., Dumas, P. \& Mezouar, M. Oxygen impurities reduce the metallization pressure of xenon. Phys. Rev. B 86, 014103 (2012).

12. Weck, G., Dewaele, A. \& Loubeyre, P. Oxygen/noble gas binary phase diagrams at $296 \mathrm{~K}$ and high pressures. Phys. Rev. B 82, 014112 (2010).

13. Zhu, Q. et al. Stability of xenon oxides at high pressures. Nat. Chem. 5, 61-65 (2012).

14. Hermann, A. \& Schwerdtfeger, P. Xenon suboxides stable under pressure. J. Phys. Chem. Lett. 5, 4336-4342 (2014).

15. Peng, F., Wang, Y., Wang, H., Zhang, Y. \& Ma, Y. Stable xenon nitride at high pressures. Phys. Rev. B 92, 094104 (2015).

16. Somayazulu, M. et al. Pressure-induced bonding and compound formation in xenon-hydrogen solids. Nat. Chem. 2, 50-53 (2010).

17. Miao, M. S. et al. Anionic chemistry of noble gases: formation of $\mathrm{Mg}-\mathrm{NG}$ (NG $=\mathrm{Xe}, \mathrm{Kr}, \mathrm{Ar}$ ) compounds under pressure. J. Am. Chem. Soc. 137, 14122-14128 (2015).

18. Ozima, M. \& Podosek, F. A. Formation age of Earth from 129I/127I an d $244 \mathrm{Pu} / 238 \mathrm{U}$ systematics and the missing Xe. J. Geophys. Res. 104, 25493-25499 (1999).

19. Anders, E. \& Owen, T. Mars and Earth: origin and abundance of volatiles. Science 198, 453-465 (1977).

20. Pepin, R. O. On the origin and early evolution of terrestrial planet atmospheres and meteoritic volatiles. Icarus 92, 2-79 (1991).

21. Pepin, R. O. \& Porcelli, D. Origin of noble gases in the terrestrial planets. Rev. Mineral. Geochem. 47, 191-246 (2002).

22. Caldwell, W. A. et al. Structure, bonding, and geochemistry of xenon at high pressures. Science 277, 930-933 (1997).

23. Jephcoat, A. P. Rare-gas solids in the Earth's deep interior. Nature 393, 355 (1998).

24. Lee, K. K. \& Steinle Neumann, G. High-pressure alloying of iron and xenon: 'Missing' Xe in the Earth's core? J. Geophys. Res. 111, B02202 (2006).

25. Nishio-Hamane, D., Yagi, T., Sata, N., Fujita, T. \& Okada, T. No reactions observed in Xe-Fe system even at Earth core pressures. Geophys. Res. Lett. 37, L04302 (2010).

26. Seoung, D. et al. Irreversible xenon insertion into a small-pore zeolite at moderate pressures and temperatures. Nat. Chem. 6, 835 (2014).

27. Sill, G. T. \& Wilkening, L. L. Ice clathrate as a possible source of the atmospheres of the terrestrial planets. Icarus 33, 13-22 (1978)

28. Wacker, J. F. \& Anders, E. Trapping of xenon in ice: implications for the origin of the Earth's noble gases. Geochim. Cosmochim. Acta 48, 2373-2380 (1984).

29. Matsuda, J. I. \& Matsubara, K. Noble gases in silica and their implication for the terrestrial 'missing' Xe. Geophys. Res. Lett. 16, 81-84 (1989).

30. Sanloup, C. et al. Retention of xenon in quartz and Earth's missing xenon. Science 310, 1174-1177 (2005).

31. Probert, M. An ab initio study of xenon retention in a-quartz. J. Phys.: Condens. Matter 22, 025501 (2009).

32. Dewaele, A., Pépin, C. M., Geneste, G. \& Garbarino, G. Reaction between nickel or iron and xenon under high pressure. High. Press. Res. 37, 137-146 (2017).

33. Zhu, L., Liu, H., Pickard, C. J., Zou, G. \& Ma, Y. Reactions of xenon with iron and nickel are predicted in the Earth's inner core. Nat. Chem. 6, 644-648 (2014).

34. Stavrou, E. et al. Synthesis of xenon and iron-nickel intermetallic compounds at Earth's core thermodynamic conditions. Phys. Rev. Lett. 120, 096001 (2018). 
35. $\mathrm{Hu}, \mathrm{Q}$. et al. $\mathrm{FeO}_{2}$ and $\mathrm{FeOOH}$ under deep lower-mantle conditions and Earth's oxygen-hydrogen cycles. Nature 534, 241-244 (2016).

36. Lu, C., Amsler, M. \& Chen, C. Unraveling the structure and bonding evolution of the newly discovered iron oxide $\mathrm{FeO}_{2}$. Phys. Rev. B 98, 054102 (2018).

37. Zhang, J. et al. Rare helium-bearing compound $\mathrm{FeO}_{2} \mathrm{He}$ stabilized at deepEarth conditions. Phys. Rev. Lett. 121, 255703 (2018).

38. Dewaele, A. et al. Synthesis and stability of xenon oxides $\mathrm{Xe}_{2} \mathrm{O}_{5}$ and $\mathrm{Xe}_{3} \mathrm{O}_{2}$ under pressure. Nat. Chem. 8, 784 (2016).

39. Deringer, V. L., Tchougréeff, A. L. \& Dronskowski, R. Crystal orbital Hamilton population (COHP) analysis as projected from plane-wave basis sets. J. Phys. Chem. A 115, 5461-5466 (2011).

40. Liu, Z. et al. Reactivity of He with ionic compounds under high pressure. Nat. Commun. 9, 951 (2018).

41. Bader, R. F. W. Atoms in Molecules: A Quantum Theory. (Clarendon, Oxford, UK, 1990).

42. Le Page, Y. \& Saxe, P. Symmetry-general least-squares extraction of elastic data for strained materials from ab initio calculations of stress. Phys. Rev. B 65, 104104 (2002).

43. Martorell, B., Vočadlo, L., Brodholt, J. \& Wood, I. G. Strong premelting effect in the elastic properties of hcp-Fe under inner-core conditions. Science 342, 466-468 (2013).

44. Mainprice, D. A FORTRAN program to calculate seismic anisotropy from the lattice preferred orientation of minerals. Computers Geosci. 16, 385-393 (1990).

45. Thorne, M. S. \& Garnero, E. J. Inferences on ultralow-velocity zone structure from a global analysis of SPdKS waves. J. Geophys. Res. 109, B08301 (2004).

46. Wang, Y., Lv, J., Zhu, L. \& Ma, Y. Crystal structure prediction via particleswarm optimization. Phys. Rev. B 82, 094116 (2010).

47. Wang, Y., Lv, J., Zhu, L. \& Ma, Y. CALYPSO: A method for crystal structure prediction. Comput. Phys. Commun. 183, 2063-2070 (2012).

48. Zhu, L. et al. Substitutional alloy of $\mathrm{Bi}$ and Te at high pressure. Phys. Rev. Lett. 106, 145501 (2011).

49. Li, Y., Hao, J., Liu, H., Li, Y. \& Ma, Y. The metallization and superconductivity of dense hydrogen sulfide. J. Chem. Phys. 140, 174712 (2014).

50. Peng, F. et al. Hydrogen clathrate structures in rare earth hydrides at high pressures: possible route to room-temperature superconductivity. Phys. Rev. Lett. 119, 107001 (2017).

51. Lv, J., Wang, Y., Zhu, L. \& Ma, Y. Predicted novel high-pressure phases of lithium. Phys. Rev. Lett. 106, 015503 (2011).

52. Gao, B. et al. Interface structure prediction via CALYPSO method. Sci. Bull. 64, 301 (2019).

53. Perdew, J. P. \& Wang, Y. Accurate and simple analytic representation of the electron-gas correlation energy. Phys. Rev. B 45, 13244 (1992).

54. Perdew, J. P., Burke, K. \& Ernzerhof, M. Generalized gradient approximation made simple. Phys. Rev. Lett. 77, 3865 (1996).

55. Kresse, G. \& Furthmüller, J. Efficient iterative schemes for ab initio totalenergy calculations using a plane-wave basis set. Phys. Rev. B 54, 11169 (1996).

56. Blöchl, P. E. Projector augmented-wave method. Phys. Rev. B 50, 17953 (1994).

57. Anisimov, V. I., Solovyev, I. V., Korotin, M. A., Czyżyk, M. T. \& Sawatzky, G. A. Density-functional theory and $\mathrm{NiO}$ photoemission spectra. Phys. Rev. B 48, 16929 (1993)

58. Wang, L., Maxisch, T. \& Ceder, G. Oxidation energies of transition metal oxides within the GGA+U framework. Phys. Rev. B 73, 195107 (2006).

59. Liu, J. et al. Hydrogen-bearing iron peroxide and the origin of ultralowvelocity zones. Nature 551, 494 (2017)

60. Lu, C. \& Chen, C. High-pressure evolution of crystal bonding structures and properties of FeOOH. J. Phys. Chem. Lett. 9, 2181-2185 (2018).

61. Hu, Q. et al. Dehydrogenation of goethite in Earth's deep lower mantle. Proc. Natl Acad. Sci. USA 114, 1498-1501 (2017).
62. Monkhorst, H. J. \& Pack, J. D. Special points for Brillouin-zone integrations. Phys. Rev. B 13, 5188-5192 (1976).

63. Togo, A., Oba, F. \& Tanaka, I. First-principles calculations of the ferroelastic transition between rutile-type and $\mathrm{CaCl}_{2}$-type $\mathrm{SiO}_{2}$ at high pressures. Phys. Rev. B 78, 134106 (2008).

64. Lee, K., Murray, E. D., Kong, L., Lundqvist, B. I. \& Langreth, D. C. Higheraccuracy van der Waals density functional. Phys. Rev. B 82, 081101 (2010).

65. Anzellini, S., Dewaele, A., Mezouar, M., Loubeyre, P. \& Morard, G. Melting of iron at Earth's inner core boundary based on fast X-ray diffraction. Science 340, 464-466 (2013).

\section{Acknowledgements}

We acknowledge funding from National Natural Science Foundation of China under Grant Nos. 11774140 and 11622432, China Postdoctoral Science Foundation under Grant No. 2016M590033, Natural Science Foundation of Henan Province under Grant No. 162300410199, Program for Science and Technology Innovation Talents in University of Henan Province under Grant No. 17HASTIT015, and Open Project of the State Key Laboratory of Superhard Materials, Jilin University under Grant No. 201602.

\section{Author contributions}

Q.L., C.C., and Y.M. designed the research; F.P., and X.S. performed the calculations; F.P., X.S., C.L., Q.L., M.M., C.C., and Y.M. analyzed and interpreted the data, and contributed to the writing of the paper.

\section{Competing interests}

The authors declare no competing interests.

\section{Additional information}

Supplementary information is available for this paper at https://doi.org/10.1038/s41467 020-19107-y.

Correspondence and requests for materials should be addressed to Q.L., C.C. or Y.M.

Peer review information Nature Communications thanks the anonymous reviewer(s) for their contribution to the peer review of this work. Peer reviewer reports are available.

Reprints and permission information is available at http://www.nature.com/reprints

Publisher's note Springer Nature remains neutral with regard to jurisdictional claims in published maps and institutional affiliations.

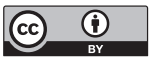

Open Access This article is licensed under a Creative Commons Attribution 4.0 International License, which permits use, sharing, adaptation, distribution and reproduction in any medium or format, as long as you give appropriate credit to the original author(s) and the source, provide a link to the Creative Commons license, and indicate if changes were made. The images or other third party material in this article are included in the article's Creative Commons license, unles indicated otherwise in a credit line to the material. If material is not included in the article's Creative Commons license and your intended use is not permitted by statutory regulation or exceeds the permitted use, you will need to obtain permission directly from the copyright holder. To view a copy of this license, visit http://creativecommons.org/ licenses/by/4.0\%.

(C) The Author(s) 2020 